\title{
Investigating Benefits and Barriers of Distance Education during Coronavirus Pandemic
}

Khalid Abdullah Alotaibi, College of Education, Al-Kharj, Prince Sattam bin Abdulaziz University, KSA, e-mail: ka.alotaibi@psau.edu.sa

\begin{abstract}
This study aims to identify benefits and barriers to distance education, particularly from the perspective of teachers in Saudi Arabia. As the applied data collection tool, a questionnaire was distributed to the general education teachers in three districts. The sample size of the study was 1076 teachers.

The results revealed that despite several benefits gained from distance learning, there are also some barriers. Teachers found that the most important advantage in distance learning is the acquisition of technical skills during the online teaching processes, they learn more and use digital education platforms, they have sufficient time to prepare the scientific content, they were able to provide adequate technical solutions for their courses, and they have the opportunity to use multiple media to deliver their courses.

With the introduction of distance learning, teachers have explored new ways to deliver course contents to students. It has fostered better ways to provide more interactive realtime and on-demand teaching and learning using modern technology, thus, helping teachers become familiar with the use of electronic resources. It seems that teachers invest in technical methods to enhance students' performance. Also, teachers reported some obstacles that they face during remote teaching. Most of these problems are connection problems applied with devices and the internet, lack of students' motivation to learn in distance, problems associated with urban learners.
\end{abstract}

Keywords: Benefits, barriers, distance education, coronavirus 


\section{Introduction}

Distance education is an option that many schools implement to enhance the delivery of learning goals. It has also been stated that online education is an effective strategy, judging from both the institution's and parents' perspectives (Hannum et al., 2008; Irvin et al., 2010). Studies showed that the most essential and prominent skill gained by all stakeholders at different levels of distance learning, especially during the Coronavirus pandemic, is the experience in the use of technology. In addition, since mobile phone is one of the most used pieces of equipment in distance learning, parents need to monitor their children to control access time and schedule to ensure that their educational goal reaches the desired level of satisfaction.

According to the United Nations Report (2020), COVID-19 pandemic has a remarkable effect on schools generally, where 190 countries were forced to suspend in-person education. Most of these countries switched to distance emergency education (United Nations, 2020). This shift in learning methods has posed specific effects on general education quality.

Today's digital education system often uses several terms, such as online, distance, flexible, open, mixed, and blended. Moreover, different terms are used to refer to online learning such as online programs and courses (Tanhan, 2020). Distance education, as a broad term, is used to describe any activities in the teaching and learning process without the need to be physically present at the school, college, or university. Other terms like distance learning, e-learning, and online learning also refer to distance education (Lee, 2010). In this way, distance learning allows interactions between students and teachers, as well as between students and devices without requiring their physical presence or both parties being online at the same time.

The unexpected change from face-to-face learning to distance education is a sign of organizational agility (Wu, 2020), as several educational institutions are primarily focused on transferring educational content from traditional to digital media to improve students' access to such content. Some institutions dealt with this change in a strategic way thus, saving time and cost. There are several advantages to distance learning, which include but are not limited to the ability to study at any time, and anywhere; flexibility in learning, affording students the time to think and respond (Xiaet al., 2013). 
Furthermore, (Lin 2015; Payne, 2020; Wang et al., 2019; Warschauer et al., 1996) indicated that students' motivation and attitudes toward learning could improve through distance education.

Due to the unplanned nature of the changes to online education, there were lack of resources in most academic institutions, inadequate access to/poor network connections, and the lack of updated technology, which affected both educational organizations and students' ability to participate in online learning (Zhong, 2020). Additionally, inadequate interaction with teachers is another concern associated with distance learning, so that those tactile students may prefer face-to-face classes. Another aspect of face-to-face learning that is found lacking in distance education is the opportunity to gain social skills within the classroom, thus students may not be able to share their ideas, information, and knowledge correctly (Britt, 2006).

\section{Research questions:}

By empirical design, this study is equipped to answer the following questions:

1. What are the consequences of distance education during the Coronavirus Pandemic?

2. What are the barriers that are facing distance learning during Coronavirus Pandemic?

3 . Is there any relationship between gender, experience, type of school, and the consequences and barriers facing distance education?

\section{Literature}

Due to the restriction in movement adopted in practically all countries during the Coronavirus pandemic, distance learning was officially adopted as an alternative and the best-suited method of education, given the pandemic situation and has nowbecome the preferred system of education in many countries around the world, consequently by shifting from regular classes to e-classes and adapting to the changing learning and teaching strategies (Carey, 2020). Distance education is a style of education, which allows students to learn at their preferred pace, time and place, which can happen with or without real-time communication with the instructor. Therefore, the use of technology in education cannot be overemphasized, especially with online learning that can assist the learner in obtaining the required knowledge and skills (Liguori \& Winkler, 2020). 
According to Sadiq (2004), distance education is a strategic interaction between students and their teachers that takes place outside the classrooms of the schools, so that knowledge and skills can reach the student through technical means or electronic media. Distance learning was defined by the Association for Distance Learning (USDLA), as the process of transferring skills, knowledge and information to learners at any level of education, using various media tools and technologies (USDLA, 2004). Certainly, the circumstance of Coronavirus (COVID-19) has a crucial impact on both persons and institutions at the different levels of the general education system around the world (Adnan \& Anwar, 2020).

There are several benefits of distance learning for all stakeholders. Since online learning is not subject to geographical location, distance education can reduce the costs and create an adequate time to give more valuable skills to students (Chen, 2011). In addition, one of the most important advantages of distance learning is that students can easily access learning materials anytime and anywhere by simply connecting to the internet (Ong et al., 2004; Al-Rahmi et al., 2018). Another benefit of distance learning as demonstrated by Ibrahim et al. (2021), is that it can foster positive emotions and economic values. Students are more likely to develop a positive disposition towards distance learning, especially when they use online educational materials positively and successfully with proper guidance (Salloum et al., 2019). Moreover, the measure of success in using distance learning is in direct proportionality with the increase in students' skills, knowledge, abilities (Al-Qahtani et al., 2013; Mohammadi, 2015).

However, some studies revealed that despite its flexibility, low cost, easy access and social benefits, there are still several problems encountered in distance learning. Researchers have found that one problem facing distance learning is the lack of students' awareness of the benefits of online education (Almaiah \& Mulhem, 2018). Additionally, increased social inequalities in some countries, which results in limited access to education (Scarpellini et al., 2021), and based on Dachyar et al., (1015), who asserted that there is a lack of adequate human resources in the application of technology to education. On the other hand, some of these problems can be overcome if students can use the distance learning system in a proper way (Pituch \& Lee, 2006; Chaka \& Govender, 2017). 
Several studies have investigated the impacts of distance learning during covid-19. Most of the challenges to distance education are primarily focused on technical issues, financial issues, information issues and personal issues (Ibrahim et al., 2021; Abuhammad, 2021; Zohra et al., 2020; Al-Kumaim et al., 2021; Anwar et al, 2020). Muhammad, and Anwar (2020), emphasized that online learning cannot fulfill the intended objectives in the underdeveloped world, where the majority of students are unable to access the internet due to technical issues as well as the high cost of accessing the internet in such countries. They also explored the lack of personal interaction with teachers, insufficient time to responses and absence of a normal classroom. In the same line, Saxena et al. (2020) revealed that distance learning is also affected by factors such as assurance, reliability, responsiveness, and website content. Some studies revealed that the quality of distance learning is lower than that of face-toface learning. Chetty et al. (2020) showed a marked decrease in student achievement level by observing students' data in mathematics before and during the Coronavirus pandemic. Some possible reasons for the low quality of online education could be the policies and procedures adopted by some countries at the time of switching to distance learning; for instance, doing homework and participation is optional and that implementation of final tests is subject to cancellation (Alzaghibi, 2021). Apparently, distance learning, in general, is not as effective as face-to-face learning, but it is undoubtedly better than nothing.

\section{Methods and Material}

\section{Sample}

The key aim of this study is to investigate the consequences of distance education on general education in schools in Saudi Arabia during the Coronavirus Pandemic. The sample of the study included 1076 teachers in primary, intermediate, and secondary schools in three provinces, which include Al-Kharj, Dilum, and Hotat Bani Tamim. All the teachers who participated in the survey are currently teaching online courses using a digital education platform. 


\section{Survey}

A 42-item Likert scale electronic questionnaire designed using google forms was adopted as the preferred data collection technique for the study. The stated questionnaire was used to examine the effectiveness of distance learning. A pilot test of the questionnaire was applied to the teachers in Al-Kharj, Dilum, and Hotat Bani Tamim provinces and appropriate reviews necessary modifications were made based on the reviewers' comments and their suggestions.,.

\section{Data Analysis}

The data collected through the online questionnaire were analyzed by descriptive statistics, mainly frequency distribution table in relation to the teachers' answers. Demographic information was collected using the Likert scale, which reported in percentages of teachers' answers. The average and standard deviations was calculated to the three pivots of the questionnaire, also a t-test and analysis of variance ANOVA test were done to examine the significant differences between participant's responses.

\section{Results}

In this section, the study focuses on descriptive statistics and inferential statistics. Descriptive statistics such as frequencies, averages, standard deviation. Inferential statistics such as t-test and analysis of variance (ANOVA). The results in table 1 present the frequency distribution of the study sample according to gender, as the number of females participating in the study was $663(61.6 \%)$, while the number of males was $41(\% 38.4)$. The governorates reported that $554(51.5 \%)$ of the study participants were from Al-Kharj Governorate, 309 (28.7\%) from Dilum Governorate, and 213 (19.8\%)from Hotat Bani Tamim Governorate.

Also included in table 1 is the frequency distribution of the sample according to the type of school. The highest number of participants were primary schools teachers, 443(41.2\%), 396(34.3\%) intermediate schools, and 264(24.5\%) secondary schools. Regarding the teachers' experience, 439 (40.8\%) have 11-20 years of experience, $378(35.1 \%)$ have less than 10 years of experience, $235(21.8 \%)$ have $21-30$ years of experience, and $24(2.2 \%)$ have more than 30 years. 
Table (1): frequency distribution of the sample according to gender

\begin{tabular}{|c|c|c|c|}
\hline & & Frequency & Percent \\
\hline & Male & 413 & 38.4 \\
\hline \multirow[t]{3}{*}{ Gender } & Female & 663 & 61.6 \\
\hline & Al-Kharj & 554 & 51.5 \\
\hline & Dilum & 309 & 28.7 \\
\hline \multirow[t]{3}{*}{ province } & That Bani Tamim & 213 & 19.8 \\
\hline & primary & 443 & 41.2 \\
\hline & Intermediate & 396 & 34.3 \\
\hline \multirow[t]{4}{*}{ School } & Secondary & 264 & 24.5 \\
\hline & Less than 10 years & 378 & 35.1 \\
\hline & $11-20$ year & 439 & 40.8 \\
\hline & 21-30 year & 235 & 21.8 \\
\hline Experience & More than30 & 24 & 2.2 \\
\hline
\end{tabular}

The results in Table 2 shows the high average mean of statements of teachers' viewpoints on the benefits of implementing distance learning (3.76). This result indicates that teachers found several advantages to distance learning during the Coronavirus pandemic. The benefits are divided into several aspects, such as stakeholders gain more skills in using educational technology, teachers get more time to prepare scientific/course content, students have more time to work on their tasks while getting immediate feedback from the teacher, also, students can be monitored by teachers. 
Table (2): The benefits of implicating distance education

Standard

Statement

Average deviation

Ranking

Provide teachers with skills to use technology in learning processes.

4.52

0.61

Very

Providing teachers with the skills of using educational

0.60

high

platforms.

Provides sufficient time for teachers to prepare the

0.74

Very

scientific content for the courses.

Introduce teachers to some technical solutions for

educational uses.

4.29

0.70

high

Very

high

Very

high

Distance learning provides flexibility in using multiple media to explain the course material.

0.82

High

It enables learners to perform assignments and assignments on time.

0.95

High

Introduce teachers to some technical solutions for

educational uses.

3.93

0.89

High

Facilitate monitoring of learners' performance online.

3.85

1.04

High

Provides sufficient time for teachers to prepare the scientific content for the courses.

3.84

1.02

High

Provide learners with first-hand feedback.

3.80

0.92

High

Allow sufficient time for the teacher to enrich the course content.
High 
It contributes to increasing the interaction of electronic learners with the scientific material.

3.69

1.06

High

Diversity of electronic assessment methods to

evaluate the learning process

1.15

High

Being able to implement practical applications of the courses in an applied manner.

3.60

1.01

High

\section{General Average}

3.76

High

The results in Table 3 shows the obstacles faced by teachers in distance education. The teachers had practically the same view in all statements in this section with a high average mean (3.59). Although, of the several advantages mentioned earlier, there are some barriers shown in this table. Teachers mentioned that technical problems, lack of technical support, lack of supporting materials, especially assessment methods, the existence of educational loss, difficulty in preparing a suitable environment. In addition to the barriers related to stakeholders, weak technical background, lack of motivations in students as well as in teachers.

Table (3): The barriers to distance education

Standard

Statement

Average deviation Ranking

Continuous remote connection problems

(devices, internet, applications, ...).

4.08

1.02

High

Low motivation for some students to learn from

distance.

1.05

High

The need of some learners for direct (urban)

education. 
It is difficult for some students to understand some subjects in the absence interaction in classroom.

3.88

1.21

High

The lack of electronic devices for some of the learners.

3.86

1.03

High

Weak technical background of teachers before adopting distance education.

3.78

0.02

High

Poor technology skills for learners and parents.

3.68

1.09

High

Lack of reliability with remote evaluation methods.

High

Resistance of learners to adapt to the distance learning strategy.

High

The lack of uniform controls for the use of electronic media.

0.96

High

Weak technical support for using the platform.

1.07

High

Home environment is not suitable for students to learn in remotely.

$1.20 \quad$ Medium

Not preparing the school community for distance learning.

1.10

Medium

The presence of an educational lost in distance education.

Medium

The lack of diversity of evaluation models for learners in the distance education.

Difficulty in learning some practical courses remotely. 
Difficulty delivering scientific content to students remotely.

Medium

\section{General Average}

3.59

High

Table 4 shows the results for the suggestions to improve all processes involved in distance education. It recorded that the average mean is high (3.48), which means that the teachers have the same views for suggestions to enhance the management of distance learning. Some of the suggested ideas to improve the management of distance learning includes providing continuous technical support as well as educational support for all users, designing educational channels related to courses, raising community awareness towards distance education, motivating schools to create smart techniques in online learning and designing training programs for all stakeholders. 
Table (4): The suggestions for developing distance education processes

\section{Statement}

Providing direct technical support at any time.

Putting videos explaining the study materials on

YouTube channels.

Improving the level of support services that support distance education operations.

Raising the level of positive trends towards distance education.

Employing the mass media in raising awareness of the importance of optimal use of distance education tools.

Motivating the distinguished school community in the application of distance education processes.

Establishing community partnerships with companies and technical institutions in the field of distance education.

Intensifying training programs in distance education for stakeholders.

Preparing various question forms for all courses.

Continuing to provide feedback to raise the level of application of distance education processes.

\section{Average Standard Ranking deviation}

4.45

4.42

3.36

0.69

Medium

0.71

Medium

3.31

0.74

Medium

$0.75 \quad$ Medium

$0.76 \quad$ Medium

$\begin{array}{lll}3.26 & 0.78 \quad \text { Medium }\end{array}$

0.75

Medium

3.15

0.86 Medium 


\section{Testing the significance of the differences}

The results in table 5 reveals that there are no statistically significant differences between the participant's viewpoints in relation to gender (male-female). This means that gender has no effect on teachers' attitudes towards distance education.

Table (5) t-test for differences between means in relation to gender

\begin{tabular}{clllll}
\hline Gender & $\mathrm{N}$ & mean & SD & t-value & sig \\
\hline Male & 413 & 164.9 & 15.3 & & \\
Female & 663 & 163.7 & 16.2 & 1.26 & 0.207
\end{tabular}

The results in table 6 shows that there are no statistically significant differences between the participant's perspectives in terms of their years of experience. This result indicates that there is no relation between years of experience and teachers' attitudes towards distance learning. Consequently, the opinions of the participants are homogeneous regardless of their working experience

Table (6): analysis of variance (ANOVA) for the differences in relation to years of experience

\begin{tabular}{|l|l|l|l|l|l|l|}
\hline Variable & $\begin{array}{l}\text { Source of } \\
\text { variation }\end{array}$ & $\begin{array}{l}\text { Sum of } \\
\text { squares }\end{array}$ & Df & $\begin{array}{l}\text { Mean } \\
\text { sum of } \\
\text { squares }\end{array}$ & $F$ & Sig \\
\hline \multirow{2}{*}{ Experience } & $\begin{array}{l}\text { Between } \\
\text { groups }\end{array}$ & 52.959 & 2 & 26.479 & \multirow{2}{*}{0.104} & 0.901 \\
\cline { 2 - 6 } & Within groups & 272929.9 & 1073 & 254.361 & & \\
\cline { 2 - 6 } & Total & 272982.836 & 371 & & & \\
\hline
\end{tabular}

The results in table 7 shows that there are no statistically significant differences between the participant's viewpoints in relation to type of school. This result indicates 
that the school level (primary - intermediate - high) does not affect teachers' attitudes towards distance education.

Table 7: Results of analysis of variance (ANOVA) for the differences in participants' opinions in relation to the type of school

\begin{tabular}{|l|l|l|l|l|l|l|}
\hline Variable & $\begin{array}{l}\text { Source of } \\
\text { variation }\end{array}$ & $\begin{array}{l}\text { Sum of } \\
\text { squares }\end{array}$ & Df & $\begin{array}{l}\text { Mean } \\
\text { sum of } \\
\text { squares }\end{array}$ & F & Sig \\
\hline \multirow{2}{*}{ Type of school } & $\begin{array}{l}\text { Between } \\
\text { groups }\end{array}$ & 720.726 & 3 & 240.242 & \multirow{2}{*}{0.946} & 0.418 \\
\cline { 2 - 6 } & Within groups & 272262.11 & 1072 & 253.976 & \\
\cline { 2 - 6 } & Total & 272982.836 & 371 & & \\
\hline
\end{tabular}

\section{Discussion}

This study aimed to investigate the effects and consequences of distance learning during the Coronavirus pandemic among Saudi teachers in three provinces. This disease has changed the education system around the world. As a result, shifting to online learning was the best solution to continue educational journey. However, several negative effects were encountered through this shifting. The results in this study revealed that despite gaining benefits from distance learning, some barriers were also encountered. In addition, several suggestions and initiatives were also revealed in this study.

Teachers found that the most important advantage of distance learning is the technical skills and experiences acquired in their teaching processes, they learned more and used educational platforms different than they've used before, they had sufficient time to prepare scientific content, they can provide sufficient technical solution of their courses, 
and they also learned to use multiple media to explain the courses. These results are in agreement with other studies, such as İbrahim et al. (2021) and Cheng (2011).

With distance education, teachers have explored a new way to deliver their course content to students. Therefore, teachers have become familiar with electronic resources. In addition, teachers can interact and deal with technologies when they teach their students. It seems that teachers invest more in technical methods to enhance students' performance.

On the other hand, teachers reported some obstacles they faced during their remote teaching sessions. Most of these problems are connection problems with devices and the internet, lack of students' motivation to learn from a distance, problems associated with urban learners, some students have difficulties understanding out-of-class teaching, and some students do not own electronic devices. These results were also confirmed by other studies, Zohra et al. (2020) and Lassoued et al. (2020).

It is basically expected that difficulties and challenges are imminent when adopting a new strategy without proper preparation, as most teachers have not previously engaged in remote teaching and they have also not used technology to deliver their course content. Consequently, designing training programs for both the short and long term may increase the awareness and raise the experiences of stakeholders.

Finally, the teachers proposed certain ideas and suggestions to improve distance learning, providing continuous technical support for all stakeholders, designing TV channels specifically for introducing and delivering course content. Furthermore, teachers made other suggestions, like providing more services to support the educational operations, raising community awareness and sensitivity towards distance learning, and investing in all types of media to enhance distance education.

Adopting such suggestions may increase the benefits of distance education. Following all positive points and solving all negative sides is the way to enhance online learning in schools to improve students' achievement. In addition, institutional communities should 
contribute in their own way, imbibing online education culture whether there are diseases (pandemic) or not.

\section{Conclusion}

This study aimed to examine the effects and consequences of distance education during Coronavirus Pandemic in three provinces in Saudi Arabia (Al-Kharj, Dilum, and Hotat Bani Tamim). The study revealed that teachers acquired valuable benefits, especially in adopting technology in education at different levels. Additionally, teachers face some barriers when they teach from a distance, such as remote connection problems and lack of knowledge in online education. It is possible to increase the usage of technology in education positively by adopting the suggested initiatives made in this study.

\section{References}

Abu Hammad, Sawsan (2020).Barriers to distance learning during the COVID-19 outbreak: A qualitative review from parents' perspective, Heliyon 6 (2020) e05482, https://doi.org/10.1016/j.heliyon.2020.e05482.

Adnan, Muhammad and Anwar ,Kainat (2020). Online learning amid the COVID-19 pandemic: Students' perspectives, Journal of Pedagogical Sociology and Psychology Volume 2, Issue 1,2020 http://www.doi.org/10.33902/JPSP. 2020261309.

Almaiah, D.R.M.A., Mulhem, D.R.A.A.L., 2018. A Conceptual Framework for Determining the Success Factors of e-Learning System Implementation using Delphi Technique.

Al-Rahmi, W.M., Alias, N.B., Othman, M.Z., Alzahrani, A.I., Alfarraj, O., Saged, A.A.G., Rahman, N.S.A., 2018. Use of E-Learning by University Students in Malaysian Higher Educational Institutions: A Case in University Technology Malaysia. IEEE Access, Volume 6, pp. 14268- 14276.

Al-Qahtani, M., Al-Qahtani, M., Al-Misehal, H., 2013. Learner Satisfaction of E-Learning in Workplace: Case of Oil Company in Middle East. In: The 10th International Conference on Information Technology: New Generations, pp. 294-298. 
Alzaghibi, M. (2021). Learning Loss during COVID 19: concept, estimation, consequences, and catch-up strategies.

Al-Kumaim, Nabil Hasan, Fathey Mohammed, Nadhmi A. Gazem, Yousef Fazea, Abdulsalam K. Alhazmi, and Omar Dakkak(2021).Exploring the Impact of Transformation to Fully Online Learning During COVID-19 on Malaysian University Students' Academic Life and Performance, iJIM - Vol. 15, No. 05, 2021. Adnan, Muhammad, and Anwar, Kainat (2020). Online learning amid the COVID-19 pandemic: Students' perspectives, Journal of Pedagogical Sociology and Psychology Volume 2, Issue 1,2020 http://www.doi.org/10.33902/JPSP. 2020261309.

Britt, R. (2006). Online education: A survey of faculty and students. Radiologic Technology, 77(3), 183- 190.

Carey, K. Is Everybody Ready for the Big Migration to Online College? Actually, No; The New York Times: Washington, DC, USA, 2020.

Chen, J.-L., 2011. The Effects of Education Compatibility and Technological Expectancy on e-Learning Acceptance. Computers \& Education, Volume 57(2), pp. 1501-1511.

Chaka, J.G., Govender, I., 2017. Students' Perceptions and Readiness Towards Mobile Learning in Colleges of Education: A Nigerian Perspective. South African Journal of Education, Volume 37, pp. 1-12.

Charu Saxena, Hasnan Baber, and Pardeep Kumar (2020). Examining the Moderating Effect of Perceived Benefits of Maintaining Social Distance on E-learning Quality During COVID-19 Pandemic, Journal of Educational Technology Systems 0(0) 1-23.

Chetty, R., Friedman, J., Hendren, N., \& Stepner, M. (2020). The Economic Impacts of COVID-19: Evidence from a New Public Database Built from Private Sector Data. Retrieved Feb 11, 2021, from: https://opportunityinsights.org/wp-content/uploads/ 2020/05/tracker_paper.pdf

$\mathrm{Wu}, \mathrm{Z}$. (2020). How a top Chinese university is responding to coronavirus. Retrieved from World Economic Forum: https://www.weforum.org/agenda/2020/03/coronaviruschina-the-challenges-of-online-learning-for-universities/.

Dachyar, M., Yadrifil, Pratama, N.R., 2015. Development of Strategy Model for Organizational. International Journal of Technology, Volume 6(2), pp. 284-290. 
Doyumgac, Ibrahim; Tanhan, Ahmed \& Mustafa Said Kiymaz3 (2021). Understanding the Most Important Facilitators and Barriers for Online Education during COVID-19 through Online Photovoice Methodology, International Journal of Higher Education, Vol. 10, No. 1.

Education in Time of Emergencies and Crises, journal of Educational Sciences, Special Issue, Volume 33, No. 3, pp. 543 - 577, Riyadh.

Hannum, W.H., Irvin, M.J., Lei, P.W., Farmer, T.W., 2008. Effectiveness of using learner centered principles on student retention in distance education courses in rural schools. Dist. Educ. 29 (3), 211-229.

Irvin, M.J., Hannum, W.H., de la Varre, C., Farmer, T.W., 2010. Barriers to distance education in rural schools. Q. Rev. Dist. Educ. 11 (2), 73-78.

Lee, J. W. (2010). Online support service quality, online learning acceptance, and student satisfaction. Internet and Higher Education, 13, 277-283.

https://doi.org/10.1016/j.iheduc.2010.08.002.

Lin, H. (2015). Computer-mediated communication (CMC) in L2 oral proficiency development: A meta-analysis. ReCALL, 27(3), 261-287. https://doi.org/10.1017/S095834401400041X.

Lassoued, Zohra, Alhendawi, Mohammed, Bashitial, Raed (2020). An Exploratory Study of the Obstacles for Achieving Quality in Distance Learning during the COVID-19 Pandemic, Educ. Sci. 2020, 10, 232; doi:10.3390/educsci10090232.

Liguori, E.W.; Winkler, C. From offline to online: Challenges and opportunities for entrepreneurship education following the COVID-19 pandemic. Entrep. Educ. Pedagog. 2020.

Payne, J. S. (2020). Developing L2 productive language skills online and the strategic use of instructional tools. Foreign Language Annals. https://doi.org/10.1111/flan.12457.

Saykılı, A. (2018). Distance education: Definitions, generations, key concepts, and future directions. International Journal of Contemporary Educational Research, 5(1), 217. 
Salloum, S.A., Al-Emran, M., Shaalan, K., Tarhini, A., 2019. Factors Affecting the Elearning Acceptance: A Case Study from UAE. Education and Information Technologies, Volume 24(1), pp. 509-530.

Sadiq, A. Theoretical Foundations of Distance Education. Teacher Magazine. 2004. Available online: http://www.almaulem. netAl- (accessed on 17 May 2020).

Tanhan, A. (2020). COVID-19 surecinde online seslifoto (OSF) yöntemiyle biyopsikososyal manevi ve ekonomik meseleleri ve genel iyi oluş düzeyini ele almak: OSF'nin Turkçeye uyarlanması. [Utilizing online photovoice (OPV) methodology to address biopsychosocial spiritual economic issues and wellbeing during COVID-19: Adapting OPV to Turkish.] Turkish Studies, 15(4), 1029-1086. https://doi.org/10.7827/TurkishStudies.44451.

USDLA (US American Distance Education Association). Definition of Distance Learning. 2004.

Available online: http//www.usdla.org/ (accessed on 20 May 2020).

United Nation. (2020). Education during COVID-19 and beyond, UN Policy Brief. Retrieved Feb22,2021,from:https://www.un.org/development/desa/dspd/wpcontent/uploads/sites/22/2020/08/sg policy brief covid-

19 and education august 2020.pdf

Warschauer, M., Turbee, L., \& Roberts, B. (1996). Computer learning networks and student empowerment. System, 24, 1-14. https://doi.org/10.1016/0346- 251X (95)00049-P.

Wang, C., Hsu, H. C. K., Bonem, E. M., Moss, J. D., Yu, S., Nelson, D. B., \& LevesqueBristol, C. (2019). Need satisfaction and need dissatisfaction: A comparative study of online and face-to-face learning contexts. Computers in Human Behavior, 95, 114-125. https://doi.org/10.1016/j.chb.2019.01.034.

Zhong, R. (2020, March 17). The coronavirus exposes education's digital divide. Retrieved from The New York Times: https://www.nytimes.com/2020/03/17/technology/china-schools-coronavirus.html. 